\title{
C-13 NMR Spectra and Spin-Lattice Relaxation Times of Poly(alkyl vinyl ether)s
}

\author{
Koichi Hatada, Tatsuki Kitayama, Nobutaka Matsuo, \\ and Heimei YUKI \\ Department of Chemistry, Faculty of Engineering Science, \\ Osaka University, Toyonaka, Osaka 560, Japan
}

(Received May 6, 1983)

\begin{abstract}
C}$ NMR spectra of isotactic-rich poly(alkyl vinyl ether)s were measured in toluene- $d_{8}$ at $110^{\circ} \mathrm{C}$, with some improvements on peak separation. The ${ }^{13} \mathrm{C}$ spin-lattice relaxation times $\left(T_{1}\right.$ 's) for syndiotactic sequences were consistently longer than those for isotactic ones, in contrast to the case of polypropylene and polymethacrylates, in which the $T_{1}$ 's for isotactic sequences are longer than those for syndiotactic sequences. The nuclear Overhauser enhancement factors for the polymers of methyl and $t$-butyl vinyl ethers were close to the theoretical maximum. These results indicate higher flexibility of the syndiotactic sequences in poly(alkyl vinyl ether)s.

KEY WORDS Carbon-13 NMR Relaxation / Tacticity / NMR Chemical Shift / Methyl Vinyl Ether Polymer / Ethyl Vinyl Ether Polymer / Isopropyl Vinyl Ether Polymer / Isobutyl Vinyl Ether Polymer / $t$-Butyl Vinyl Ether Polymer / Alkyl Vinyl Ether Polymer / Nuclear Overhauser Enhancement (NOE) /
\end{abstract}

NMR spin-lattice relaxation times ( $T_{1}$ 's) of certain vinyl polymers are known to depend on stereoregularity. Thus, it has been shown for the polymers of propylene,$^{1}$ methyl ${ }^{2-5}$ and other alkyl methacrylates, ${ }^{4}$ and vinyl chloride ${ }^{6}$ that $T_{1}$ values for isotactic polymers or sequences are larger than those for syndiotactic polymers or sequences. This difference may be attributed to the fact that isotactic chains are more flexible than syndiotactic chains.

Recently, Angad-Gaur and Sikkema ${ }^{7}$ reported that $T_{1}$ for the peak of racemo methylene carbon is longer than that for the meso peak in poly(allyl vinyl ether). They accounted for this reverse phenomenon by the higher magnetic field (6.34T) employed in the measurements and concluded that the mobility of the syndiotactic sequence is lower than that of the isotactic one.

In this study, the ${ }^{13} \mathrm{C} T_{1}$ 's for poly(alkyl vinyl ether)s (alkyl=methyl, ethyl, isopropyl, isobutyl and $t$-butyl) were measured in toluene- $d_{8}$ at $110^{\circ} \mathrm{C}$ at $25 \mathrm{MHz}$. It was found that for most of the carbons in these polymers, ${ }^{13} \mathrm{C} T_{1}$ 's are shorter for isotactic or meso sequences than for syndiotactic or racemo sequences. Nuclear Overhauser enhancement (NOE) factors were measured for the polymers of methyl and $t$-butyl vinyl ethers. From the results obtained, it was concluded that in the poly(alkyl vinyl ether)s studied, the isotactic or meso sequences are less flexible than the syndiotactic or racemo sequences, in contrast to the case of polypropylene and polymethacrylates.

\section{EXPERIMENTAL}

\section{Materials}

Isopropyl and $t$-butyl vinyl ethers were synthesized from the corresponding alcohols and methyl vinyl ether by transetherification reaction. ${ }^{8}$ Other monomers were obtained from commercial sources. All these monomers were purified by fractional distillation, dried over molecular sieves $4 \mathrm{~A}$ and calcium dihydride, and distilled in vacuo before use.

Polymer samples were prepared by polymerizing these monomers with boron trifluoride etherate in toluene at $-78^{\circ} \mathrm{C}$. Their characteristics are summarized in Table I. 
Table I. Characteristics of poly(alkyl vinyl ether)s prepared with $\mathrm{BF}_{3} \cdot \mathrm{O}\left(\mathrm{C}_{2} \mathrm{H}_{5}\right)_{2}$ in toluene at $-78^{\circ} \mathrm{C}$

\begin{tabular}{lrrrrr}
\hline & \multicolumn{3}{c}{ Tacticity $/ \%$} & & \multicolumn{1}{c}{$T_{\mathrm{g}}$} \\
\cline { 2 - 4 } \cline { 5 - 6 } Alkyl group & $\mathrm{I}$ & $\mathrm{H}$ & $\mathrm{S}$ & & ${ }^{\circ} \mathrm{C}$ \\
\hline $\mathrm{CH}_{3}$ & 62 & 30 & 8 & 16100 & -27 \\
$\mathrm{C}_{2} \mathrm{H}_{5}$ & 55 & 37 & 8 & 37300 & -31 \\
iso- $_{3} \mathrm{H}_{7}$ & 62 & 24 & 14 & 26500 & -1 \\
iso- $\mathrm{C}_{4} \mathrm{H}_{9}$ & 67 & 24 & 9 & 74500 & -14 \\
$t-\mathrm{C}_{4} \mathrm{H}_{9}$ & 69 & 25 & 6 & 64300 & 82 \\
\hline
\end{tabular}

\section{Measurements}

${ }^{13} \mathrm{C}$ NMR spectra were measured on a JNMFX100 $(25 \mathrm{MHz})$ or JNM-FX200 $(50 \mathrm{MHz})$ Fourier transform NMR spectrometer (JEOL) at $110^{\circ} \mathrm{C}$. Tetramethylsilane (TMS) was used as the internal standard. A given polymer solution $\left(1.0 \mathrm{moll}^{-1}\right)$ was sealed in an NMR sample tube ( $10 \mathrm{~mm}$ o.d.) under nitrogen atmosphere. Spin-lattice relaxation times were determined by the inversion recovery method. Nuclear Overhauser enhancement factors were determined by comparing the signal intensities of completely decoupled and gated decoupled NMR spectra.

The number-average molecular weight of each sample was measured in benzene at $42.0^{\circ} \mathrm{C}$ using a Hitachi 117 vapor pressure osmometer.
Glass transition temperature was measured with a Rigaku Denki differential scanning calorimeter Model $8801 \mathrm{SL} / \mathrm{C}$ at a heating rate of $10^{\circ} \mathrm{C} \mathrm{min}-1$.

\section{RESULTS AND DISCUSSION}

\section{${ }^{13}$ C NMR Spectra of Poly(alkyl vinyl ether)s}

The ${ }^{13} \mathrm{C}$ NMR spectrum of poly(methyl vinyl ether) was first reported by Johnson et al. ${ }^{9}$ and showed in the methoxy and methylene carbon resonances stereochemical splittings which could be attributed to pentad and dyad sequences, respectively. The dyad splitting of the methylene resonance was supported by the theoretical investigation of Ando et al. ${ }^{10}$ using a dimer model. Matsuzaki and his coworkers ${ }^{11}$ measured the NMR spectra of several poly(alkyl vinyl ether)s in mixed solvents mostly containing halomethanes at $50^{\circ} \mathrm{C}$, and made the stereochemical assignments for the polymers of different tacticities. The ${ }^{13} \mathrm{C}$ NMR spectra of the polymers of ethyl and isobutyl vinyl ethers were also measured by Randall. ${ }^{12}$ In this work, we reexamined the ${ }^{13} \mathrm{C}$ NMR spectra of various poly(alkyl vinyl ether)s in toluene- $d_{8}$ at $110^{\circ} \mathrm{C}$ and found some improvements on peak separation.

Figure 1 illustrates the 25 and $50 \mathrm{MHz}^{13} \mathrm{C} \mathrm{NMR}$ spectra of poly(methyl vinyl ether) in toluene- $d_{8}$ at $110^{\circ} \mathrm{C}$. The resonances of all carbons are sensitive to
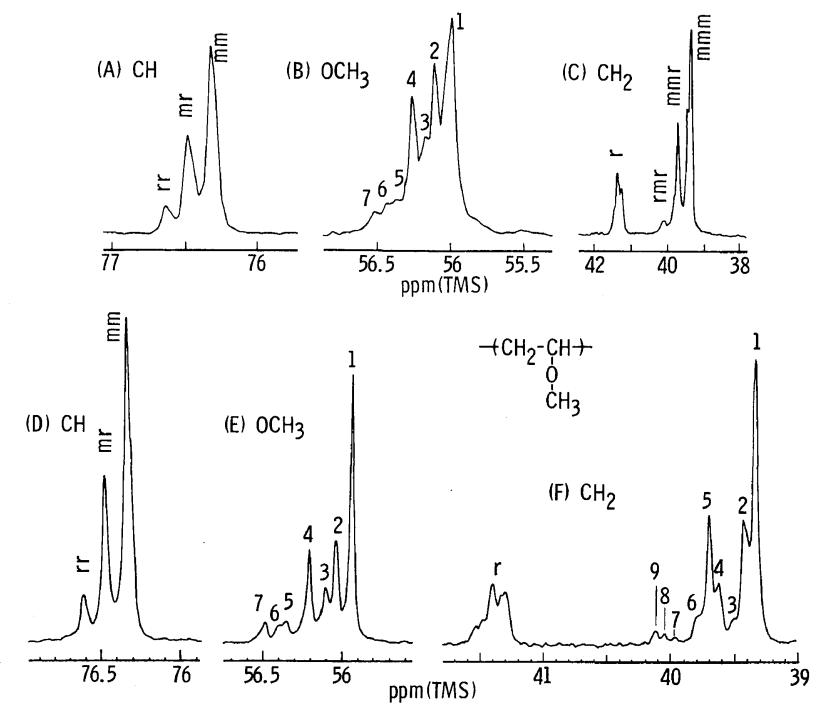

Figure 1. ${ }^{13} \mathrm{C}$ NMR spectra of poly(methyl vinyl ether) (A), (B), and (C) at $25 \mathrm{MHz},(\mathrm{D})$, (E), and (F) at $50 \mathrm{MHz}$. 
${ }^{13} \mathrm{C}$ NMR Spectra and $T_{1}$ of Poly(vinyl ether)s

Table II. Peak assignments for methoxy carbon resonance of poly(methyl vinyl ether) at $50 \mathrm{MHz}$

\begin{tabular}{|c|c|c|c|c|}
\hline \multirow{2}{*}{ Peak } & \multirow{2}{*}{$\begin{array}{c}\text { Chemical } \\
\text { shift } \\
\text { (ppm) }\end{array}$} & \multirow{2}{*}{ Assignment } & \multicolumn{2}{|c|}{ Relative intensity } \\
\hline & & & Obsd & Calcd $^{\mathrm{a}}$ \\
\hline 1 & 55.94 & $m m m m$ & 0.40 & 0.413 \\
\hline 2 & 56.06 & $m m m r$ & 0.21 & 0.192 \\
\hline 3 & 56.14 & $r m m r$ & 0.10 & 0.085 \\
\hline 4 & 56.21 & $m m r m+m m r r^{\mathrm{b}}$ & 0.17 & 0.173 \\
\hline 5 & 56.32 & $m r m r+m r r m^{\mathrm{b}}$ & 0.05 & 0.068 \\
\hline 6 & 56.39 & $m r r r$ & 0.04 & 0.038 \\
\hline 7 & 56.48 & $r r r r+r m r r$ & 0.03 & 0.031 \\
\hline
\end{tabular}

a Calculated assuming first-order Markovian statistics $\left(P_{m / r}=0.209, P_{r / m}=0.604\right)$.

b This assignment of $m m r r$ and $m r r m$ pentads is tentative and interchangeable.

Table III. Peak assignment for meso methylene carbon resonance of poly(methyl vinyl ether) at $50 \mathrm{MHz}$

\begin{tabular}{|c|c|c|c|c|}
\hline \multirow{2}{*}{ Peak } & \multirow{2}{*}{$\begin{array}{c}\text { Chemical } \\
\text { shift } \\
\text { (ppm) }\end{array}$} & \multirow{2}{*}{ Assignment } & \multicolumn{2}{|c|}{ Relative intensity } \\
\hline & & & Obsd & Calcd $^{\mathrm{a}}$ \\
\hline 1 & 39.37 & $\mathrm{mmmmm}$ & 0.307 & 0.327 \\
\hline 2 & 39.46 & $m m m m r$ & 0.160 & 0.157 \\
\hline 3 & 39.54 & $r m m m r$ & 0.025 & 0.019 \\
\hline 4 & 39.67 & $m m m r r$ & 0.064 & 0.067 \\
\hline 5 & 39.73 & $m m m r m+r m m r r$ & 0.150 & 0.143 \\
\hline 6 & 39.83 & rmmrm & 0.033 & 0.030 \\
\hline 7 & 40.02 ) & & 0.008 & \\
\hline 8 & 40.09 & $r m r$ & $0.010\}$ & 0.029 \\
\hline 9 & 40.17 & & 0.014 J & \\
\hline
\end{tabular}

a Calculated assuming first-order Markovian statistics $\left(P_{m / r}=0.209, P_{r / m}=0.604\right)$.

stereochemical configurations, and the separation of peaks is better in the spectrum at $50 \mathrm{MHz}$ than in that at $25 \mathrm{MHz}$.

It can be seen from Figure 1 that the resonance of methine carbon splits into three peaks which can be assigned to isotactic, heterotactic and syndiotactic triads in order of decreasing magnetic field. The resonance of methoxy carbon splits into pentad peaks (Figures 1B and 1E), as has already been reported..$^{9,11}$ By assuming first-order Markovian statistics, ${ }^{11}$ pentad fractions were calculated from the triad values, and the calculated values were

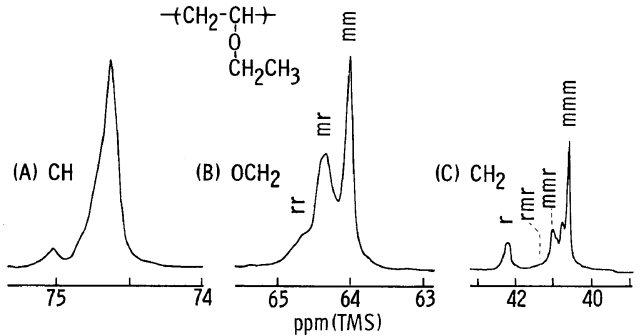

Figure 2. ${ }^{13} \mathrm{C}$ NMR spectra of poly(ethyl vinyl ether).

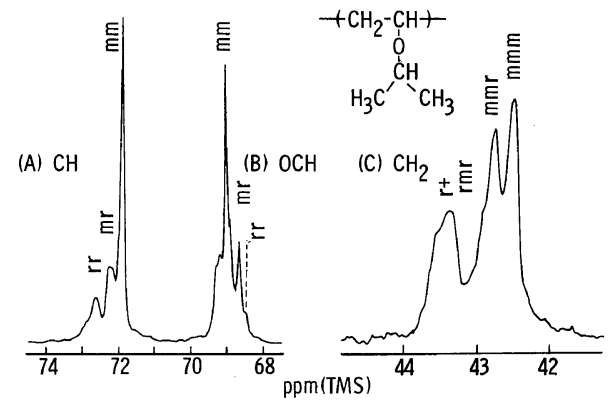

Figure 3. ${ }^{13} \mathrm{C}$ NMR spectra of poly(isopropyl vinyl ether).

compared with the measured peak intensities at $50 \mathrm{MHz}$. The resulting assignment of seven peaks is presented in Table II. The agreement between the calculated and measured intensities is fairly good. The present assignment is somewhat different from that made on the spectrum measured in a methanol-dichloromethane mixture at $50^{\circ} \mathrm{C} .^{11}$

The methylene carbon resonance consists of two multiplets situated at 39.5 and $41.4 \mathrm{ppm}$ due to dyad tacticity. The resonance of meso methylene carbon splits into nine peaks. These peaks were assigned to hexad sequences as indicated in Table III by comparing the peak intensities with the calculated fractions of hexad sequences. The racemo resonance also shows splitting probably due to hexad sequences, although peak separation was not satisfactory enough to make complete stereochemical assignment of the peaks.

${ }^{13} \mathrm{C}$ NMR spectra of the polymers of ethyl, isopropyl, isobutyl and $t$-butyl vinyl ethers were also measured in toluene- $d_{8}$ at $25 \mathrm{MHz}$ and $110^{\circ} \mathrm{C}$. The results are shown in Figures 2-5. The resonances of main-chain methylene carbons except for that of poly( $t$-butyl vinyl ether) clearly show dyad splitting. The meso methylene resonances are more 


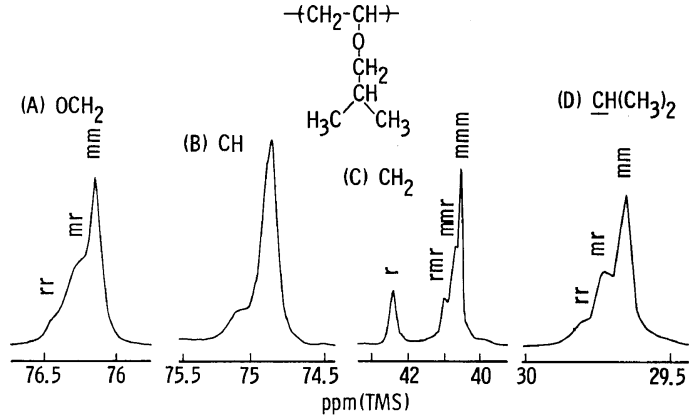

Figure 4. ${ }^{13} \mathrm{C}$ NMR spectra of poly(isobutyl vinyl ether).

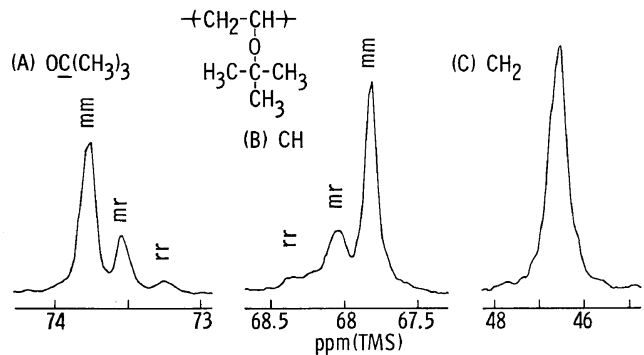

Figure 5. ${ }^{13} \mathrm{C}$ NMR spectra of poly $(t$-butyl vinyl ether).

sensitive to tetrad configurations than the racemo methylene resonances and split into multiplets as in the case of poly(methyl vinyl ether) (Figures 2C, 3C, and $4 \mathrm{C})$. The methylene carbon of poly ( $t$-butyl vinyl ether) gives only a broad signal as has already been reported $^{11}$ (Figure 5C).

The resonances of the main-chain methine carbons of these polymers split into three peaks reflecting tactic triads. The peak resolution is good in the spectra of the polymers of isopropyl and $t$-butyl vinyl ethers (Figures $3 \mathrm{~A}$ and $5 \mathrm{~A}$ ), but not so in those of the polymers of ethyl and isobutyl vinyl ethers (Figures 2A and 4B). The resonances of the $\alpha$ carbon to the oxygen in the side-chains are sensitive to stereochemical configurations, and most of them reflect the triad tacticity of the polymers.

For poly(isopropyl vinyl ether), pentad splitting was also observed in the signal for isotactic triad (Figure 3B). For poly(isobutyl vinyl ether), the resonances of the methyl carbon as well as the methylene carbon in the side-chain showed triad splitting (Figures 4A and 4D).

Matsuzaki et al. ${ }^{11}$ found the methine carbon resonance of poly(t-butyl vinyl ether) in a mixture of chloroform and dichloromethane to split into five peaks reflecting pentad tacticity. In our spectrum, however, this resonance splits into three peaks which can be assigned to $m m, m r$, and $r r$ triads in the order of decreasing magnetic field. The triad tacticities determined from the methine carbon resonance (I 68.7, H 25.3, S 6.0\%) agreed well with those obtained from the quaternary carbon signal (I $68.8, \mathrm{H} 25.3$, S $5.9 \%$ ).

In summary, our newly observed peaks and their stereochemical assignments are as follows:

Poly(methyl vinyl ehter): $\mathrm{CH}$ (triad), $\mathrm{CH}_{2}$ (hexad)

Poly(isopropyl vinyl ether):

$\mathrm{CH}$ (triad), $\mathrm{CH}_{2}$ (tetrad)

Poly(isobutyl vinyl ether):

$\mathrm{CH}$ (triad), $\mathrm{CH}\left(\mathrm{CH}_{3}\right)_{2}$ (triad), $\mathrm{CH}_{2}$ (tetrad)

Poly( $t$-butyl vinyl ether):

$\mathrm{CH}$ (triad)

The chemical shift values are listed in Table IV.

\section{${ }^{13}$ C NMR Relaxation}

Table $\mathrm{V}$ gives the ${ }^{13} \mathrm{C}-T_{1}$ values for poly(alkyl vinyl ether)s in toluene- $d_{8}$ at $110^{\circ} \mathrm{C}$. The $T_{1}$ values for the main-chain methine carbons are about twice as large as those for the main-chain methylene carbons. This suggests that these two carbons have similar mobilities; that is, the motion of the poly(alkyl vinyl ether) backbone is essentially isotropic. The $T_{1}$ 's for the main-chain carbons decrease with increasing side-chain bulkiness $\left(\mathrm{CH}_{3}<\mathrm{C}_{2} \mathrm{H}_{5}\right.$ $<$ iso- $\mathrm{C}_{3} \mathrm{H}_{7} \leq$ iso- $\mathrm{C}_{4} \mathrm{H}_{9}<t-\mathrm{C}_{4} \mathrm{H}_{9}$ ), indicating that the segmental mobility of poly(alkyl vinyl ether) decreases with an increase in the bulkiness of the side-chain alkyl groups. A similar relation was found for polymethacrylates. ${ }^{4}$ The side-chain carbons have longer $T_{1}$ than the main-chain carbons since the former have rotational freedom.

The ${ }^{13} \mathrm{C}-T_{1}$ values for the peaks of racemo or syndiotactic sequences are larger than those for the peaks of meso or isotactic sequences except in a few cases. The ratios of these two $T_{1}$ values range from 1.1 to 1.4. Angad-Gaur and Sikkema ${ }^{7}$ reported the same dependence of $T_{1}$ on stereosequence for poly(allyl vinyl ether) at $22^{\circ} \mathrm{C}$. On the basis of the lower NOE value (2.0) at $6.34 \mathrm{~T}\left(270 \mathrm{MHz}\right.$ for ${ }^{1} \mathrm{H}$ and $68 \mathrm{MHz}$ for ${ }^{13} \mathrm{C}$ ), they concluded that the $T_{1}$ values appear to the right of the minimum point in the $\log T_{1}-\log \tau$ diagram and that the syndiotactic 
${ }^{13} \mathrm{C}$ NMR Spectra and $T_{1}$ of Poly(vinyl ether)s

Table IV. ${ }^{13} \mathrm{C}$ NMR chemical shifts (ppm) for poly(alkyl vinyl ether)s in toluene- $d_{8}$ at $110^{\circ} \mathrm{C}$ and $25 \mathrm{MHz}^{\mathrm{a}}$

\begin{tabular}{|c|c|c|c|c|c|c|c|c|}
\hline \multirow{3}{*}{$\begin{array}{l}\text { Alkyl group } \\
\mathrm{CH}_{3}\end{array}$} & \multicolumn{4}{|c|}{ Main-chain } & \multicolumn{4}{|c|}{ Side-chain } \\
\hline & \multicolumn{2}{|c|}{$\mathrm{CH}_{2}$} & \multicolumn{2}{|c|}{$\mathrm{CH}$} & \multirow[t]{2}{*}{$\mathrm{CH}_{3}{ }^{\mathrm{b}}$} & \multicolumn{2}{|r|}{ Others } & \\
\hline & $\mathrm{mmm}$ & 39.37 & $\mathrm{~mm}$ & 76.33 & & & & \\
\hline & $m m r$ & 39.73 & $m r$ & 76.49 & & & & \\
\hline & $r m r$ & 40.17 & $r r$ & 76.64 & & & & \\
\hline & $m r m$ & 41.20 & & & & & & \\
\hline & $m r r$ & 41.34 & & & & & & \\
\hline & $r r r$ & $(41.5)$ & & & & & & \\
\hline \multirow[t]{4}{*}{$\mathrm{C}_{2} \mathrm{H}_{5}$} & $\mathrm{mmm}$ & 40.54 & & & & \multirow[t]{4}{*}{$\mathrm{CH}_{2}$} & $\mathrm{~mm}$ & 64.01 \\
\hline & $m m r$ & 40.97 & & 74.65 & 16.02 & & $m r$ & 64.16 \\
\hline & $r m r$ & $(41.4)$ & & & & & $r r$ & (64.3) \\
\hline & $r$ & 42.21 & & & & & & \\
\hline \multirow[t]{3}{*}{ iso- $\mathrm{C}_{3} \mathrm{H}_{7}$} & $\mathrm{mmm}$ & 42.37 & $\mathrm{~mm}$ & 71.88 & & \multirow[t]{3}{*}{$\mathrm{CH}$} & $m m$ & 69.07 \\
\hline & $m m r$ & 42.61 & $m r$ & 72.27 & 23.46 & & $m r$ & 68.67 \\
\hline & $r$ & 43.3 & $r r$ & 72.66 & & & $r r$ & $(68.5)$ \\
\hline \multirow[t]{4}{*}{ iso- $\mathrm{C}_{4} \mathrm{H}_{9}$} & $\mathrm{mmm}$ & 40.58 & & & & \multirow[t]{3}{*}{$\mathrm{CH}$} & $\mathrm{mm}$ & 29.66 \\
\hline & $m m r$ & 40.91 & & 74.85 & 19.92 & & $m r$ & 29.75 \\
\hline & $r m r$ & 41.16 & & & & & $r r$ & 29.85 \\
\hline & $r$ & 42.41 & & & & $\mathrm{CH}_{2}$ & & 76.16 \\
\hline \multirow[t]{3}{*}{$t-\mathrm{C}_{4} \mathrm{H}_{9}$} & & & $m m$ & 67.83 & & \multirow{3}{*}{$-\mathrm{C}-$} & $\mathrm{mm}$ & 73.75 \\
\hline & & 46.54 & $m r$ & 68.30 & 30.13 & & $m r$ & 73.56 \\
\hline & & & $r r$ & $(68.6)$ & & & $r r$ & 73.28 \\
\hline
\end{tabular}

a The chemical shift values in parentheses refer to shouldered peaks.

b The chemical shift and the peak assignment for poly(methyl vinyl ether) at $50 \mathrm{MHz}$ are shown in Table II.

sequence has a longer correlation time, that is, a lower flexibility than the isotactic one.

Table VI shows the NOE and $T_{1}$ values for the polymers of methyl and $t$-butyl vinyl ethers. Even at $27^{\circ} \mathrm{C}$, the NOE values for poly (methyl vinyl ether) come close to the theoretical maximum (2.99) calculated using a model for dipolar relaxation mechanism. ${ }^{13}$ Those for poly( $t$-butyl vinyl ether) do not reach this maximum but are close to it. That the NOE values obtained are larger than those for poly(allyl vinyl ether) should reflect a higher flexibility of poly(alkyl vinyl ether)s. These results indicate that the correlation time $(\tau)$ of poly(alkyl vinyl ether) is smaller than that for the minimum $T_{1}$ value in the $\log T_{1}-\log \tau$ diagram. ${ }^{14,15}$ The $T_{1}$ values for the main-chain carbons change with the glass transition temperatures of the polymers (Tables I and $\mathrm{V}$ ). This is additional evidence that the $T_{1}$ values appear to the left of the minimum $T_{1}$ value.
Therefore, it may be concluded that in the poly(alkyl vinyl ether) chains, the syndiotactic sequence has a higher mobility than the isotactic one.

In all the cases so far reported $^{1-6}$ where $T_{1}$ depends on the stereosequence of the polymers, the isotactic sequence gave a longer ${ }^{13} \mathrm{C}-T_{1}$, and hence was more flexible than the syndiotactic one. The finding that the syndiotactic sequence is more flexible than the isotactic one is probably the first instance showing the reverse of these previous observations. The implication is that the stereoregularity dependence of chain conformation in poly(vinyl ether)s should be different from that in polymethacrylates and polypropylene. However, according to a conformational analysis of poly(alkyl vinyl ether), ${ }^{16}$ the $T G$ conformation should be preferable for meso sequences and the $T T$ conformation for racemo dyads, as in the case of polymethacrylates and polypropylene. Further in- 


\section{K. HATADA et al.}

Table V. ${ }^{13} \mathrm{C}-T_{1}$ 's (s) for poly(alkyl vinyl ether)s in toluene- $d_{8}$ at $110^{\circ} \mathrm{C}$ and $25 \mathrm{MHz}$

\begin{tabular}{|c|c|c|c|c|c|c|c|c|c|}
\hline \multirow{3}{*}{$\frac{\text { Alkyl group }}{\mathrm{CH}_{3}}$} & \multicolumn{4}{|c|}{ Main-chain } & \multicolumn{5}{|c|}{ Side-chain } \\
\hline & \multicolumn{2}{|c|}{$\mathrm{CH}_{2}$} & \multicolumn{2}{|c|}{$\mathrm{CH}$} & \multicolumn{2}{|c|}{$\mathrm{CH}_{3}{ }^{\mathrm{a}}$} & & \multicolumn{2}{|c|}{ Others } \\
\hline & $\mathrm{mmm}$ & 0.64 & $m m$ & 1.23 & (1) & 3.69 & & & \\
\hline & $m m r$ & 0.64 & $m r$ & 1.20 & (2) & 3.97 & & & \\
\hline & $m r r$ & 0.75 & $r r$ & 1.53 & (4) & 4.06 & & & \\
\hline \multirow[t]{2}{*}{$\mathrm{C}_{2} \mathrm{H}_{5}$} & $\mathrm{mmm}$ & 0.40 & & 0.73 & & 2.75 & $\mathrm{CH}_{2}$ & $m m$ & 1.19 \\
\hline & $r$ & 0.44 & & & & & & $m r$ & 1.15 \\
\hline \multirow[t]{2}{*}{ iso- $\mathrm{C}_{3} \mathrm{H}_{7}$} & $\mathrm{mmm}$ & 0.22 & $m m$ & 0.44 & & 2.22 & $\mathrm{CH}$ & & 1.02 \\
\hline & $r$ & 0.25 & $m r$ & 0.53 & & & & & \\
\hline \multirow[t]{2}{*}{ iso- $\mathrm{C}_{4} \mathrm{H}_{9}$} & $\mathrm{mmm}$ & 0.20 & & 0.40 & & 3.31 & $\mathrm{CH}_{2}$ & & 0.56 \\
\hline & $r$ & 0.25 & & & & & $\mathrm{CH}$ & & 1.80 \\
\hline \multirow[t]{2}{*}{$t-\mathrm{C}_{4} \mathrm{H}_{9}$} & & 0.10 & $m m$ & 0.17 & & 1.47 & $-\mathrm{C}-$ & $\mathrm{mm}$ & 7.14 \\
\hline & & & $m r$ & 0.20 & & & & $m r$ & 7.49 \\
\hline
\end{tabular}

a The parenthesized numbers for poly(methyl vinyl ether) refer to those in Figure 1B.

Table VI. NOE and ${ }^{13} \mathrm{C}-T_{1}(\mathrm{~s})$ values for the polymers of methyl and $t$-butyl vinyl ethers

\begin{tabular}{|c|c|c|c|c|c|c|}
\hline \multirow{2}{*}{$\begin{array}{l}\text { Alkyl } \\
\text { group }\end{array}$} & \multirow{2}{*}{$\frac{\text { Temp }}{{ }^{\circ} \mathrm{C}}$} & & \multicolumn{2}{|c|}{ Main-chain } & \multicolumn{2}{|c|}{ Side-chain } \\
\hline & & & $\mathrm{CH}_{2}$ & $\mathrm{CH}$ & $\mathrm{OCH}_{3}$ & $\mathrm{OC}\left(\mathrm{CH}_{3}\right)_{3}$ \\
\hline \multirow{6}{*}{$\mathrm{CH}_{3}$} & \multirow{3}{*}{110} & NOE & 2.9 & 3.0 & 2.8 & - \\
\hline & & & $0.64(m)$ & $1.23(\mathrm{~mm})$ & & - \\
\hline & & & $0.75(r)$ & $1.53(r r)$ & $3.69^{\mathrm{a}}$ & - \\
\hline & \multirow{3}{*}{27} & $\int \mathrm{NOE}$ & 2.8 & 2.8 & 2.6 & - \\
\hline & & \multirow{2}{*}{$\begin{array}{l}T_{1} \\
\text {. }\end{array}$} & $0.14(m)$ & \multirow{2}{*}{$0.25^{\mathrm{b}}$} & \multirow{2}{*}{$1.42^{\mathrm{a}}$} & - \\
\hline & & & $0.17(r)$ & & & - \\
\hline \multirow{2}{*}{$t-\mathrm{C}_{4} \mathrm{H}_{9}$} & \multirow{2}{*}{110} & $\int \mathrm{NOE}$ & 2.6 & 2.6 & - & 2.9 \\
\hline & & $\left\{T_{1}\right.$ & 0.10 & $0.17(\mathrm{~mm})$ & - & 1.47 \\
\hline
\end{tabular}

a $T_{1}$ values for the peak (1) seen in Figure 1B.

b Splitting due to tacticity was not observed at $27^{\circ} \mathrm{C}$.

vestigation will be necessary for giving an under- in preparing this manuscript. standing of the NMR relaxation mechanism in poly(alkyl vinyl ether)s.

Acknowledgements. The authors are grateful to Dr. H. Sato of the Faculty of Technology, Tokyo University of Agriculture and Technology, for making the measurements of $50 \mathrm{MHz}{ }^{13} \mathrm{C}$ NMR spectra and also to Mrs. F. Yano for her clerical assistance

\section{REFERENCES}

1. J. C. Randall, J. Polym. Sci., Polym. Phys. Ed., 14, 1693 (1976).

2. F. Heatley and A. Begum, Polymer, 17, 399 (1976).

3. K. Hatada, H. Ishikawa, T. Kitayama, and H. Yuki, Makromol. Chem., 178, 2753 (1977). 
4. K. Hatada, T. Kitayama, Y. Okamoto, K. Ohta, Y. Umemura, and H. Yuki, Makromol. Chem., 179, 485 (1978).

5. J. R. Lyerla, Jr. and T. T. Horikawa, J. Am. Chem. Soc., 99, 2463 (1977).

6. F. C. Schilling, Macromolecules, 11, 1290 (1978).

7. H. Angad-Gaur and D. J. Sikkema, Makromol. Chem., 181, 2385 (1980).

8. H. Yuki, K. Hatada, K. Nagata, and K. Kajiyama, Bull. Chem. Soc. Jpn., 42, 3546 (1969).

9. L. F. Johnson, F. Heatley, and F. A. Bovey, Macromolecules, 3, 175 (1970).

10. I. Ando, M. Kondo, T. Ikuta, and A. Nishioka,
Makromol. Chem., 169, 285 (1973).

11. K. Matsuzaki, H. Ito, T. Kawamura, and T. Uryu, $J$. Polym. Sci., Polym. Chem. Ed., 14, 971 (1973).

12. J. C. Randall, "Polymer Sequence DeterminationCarbon-13 NMR Method," Academic Press, New York, N. Y., 1977, pp 123-128.

13. K. F. Kuhlmann, D. M. Grant, and R. K. Harris, J. Chem. Phys., 52, 3439 (1970).

14. A. Bloembergen, E. M. Purcell, and R. V. Pound, Phys. Rev., 73, 679 (1948).

15. D. Doddrell, V. Glushko, and A. Allerhand, J. Chem. Phys., 56, 3683 (1972).

16. A. Abe, Macromolecules, 10, 34 (1977). 